\section{Make confident communication your goal for 2020}

According to a survey carried out by The Confident Dentist in 2019, 60\% of dentists sometimes found that people hadn't understood what they were saying.

To help overcome this significant challenge, Dr Barry Oulton's Confident Dentist Academy offers its 'Influencing Smiles' 2-day course, which is perfect for those in dentistry who interact with patients, team members and even their own family!

Delegates learn the skills to become a master of communication and sell with integrity, so they can lead their teams effectively, get their patients to listen, increase their private dentistry treatment acceptance, and even get more people to pay attention to them in their personal lives.

Dates for 2020 include:

$\rightarrow$ London - 14-15 February

$\rightarrow$ Birmingham - 20-21 March

$\rightarrow$ London - 19-20 June

$\rightarrow$ Belfast - 11-12 September.

For further information, visit www. theconfidentdentist.com or call 0333220 2447 or email sally@theconfidentdentist.com.

\title{
Get involved with dental implants
}

You don't need to commit to full dental implant training to get involved with the implantology field. Ten Dental+Facial offers a solution with its dedicated Implant Restoration Course (IRC) - an innovative modular programme taught over the course of a year.

Led by experienced implantologists, Dr Nikhil Sisodia and Dr Martin Wanendeya, the IRC covers the theory and practise of restoring implants - from initial diagnosis and treatment planning, to the application of the final restoration. This provides the ideal solution for clinicians looking to offer implant treatment, without having to undertake comprehensive implant surgical training.

For more information about Ten Dental+Facial and the Implant Restoration Course (IRC), email office@tendental.com or call 02076227610.
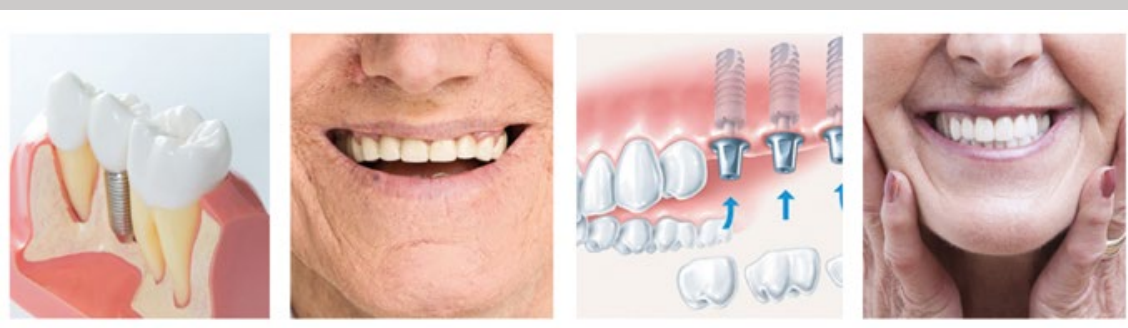

\section{Dental PPE for changing times}

A key part of avoiding infection and cross contamination in the dental practice is the quality of your protective personal equipment (PPE). The bedrock of PPE is gloves. Initial Medical has gloves for

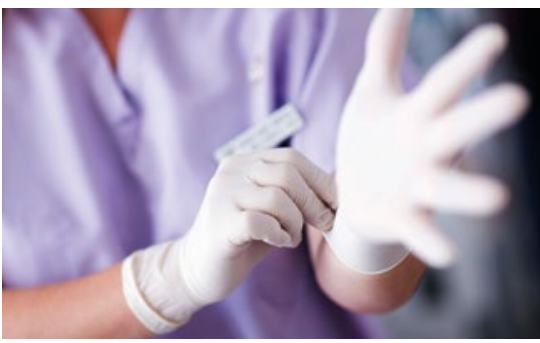

every task and every practitioner. There are various options of material (latex, non-latex, nitrile and vinyl), colours and sizes. You can choose powdered or powder free, or fragranced gloves to enhance the patient experience. Gloves from Initial Medical are safe, compliant and authenticated with the appropriate health and safety standards marks.

Choose gloves from Initial Medical for quality, comfort and to maintain the highest standards of infection control.

For further information visit www.initial. co.uk/medical.

\section{Unmatched precision}

Achieving precise impressions is always a top priority. So why not ensure accuracy and speed with Impregum Super Quick polyether impression material?

Combining the precision of a polyether with the setting speed of a VPS, Impregum Super Quick polyether impression material combines speed and efficiency to ensure that you get the outcome you need. With an intraoral setting time of just two-minutes, Impregum Super Quick polyether impression material offers superior moisture tolerance and worldfamous precision.

For more information or to request a demo visit 3M.co.uk/ImpSQ.

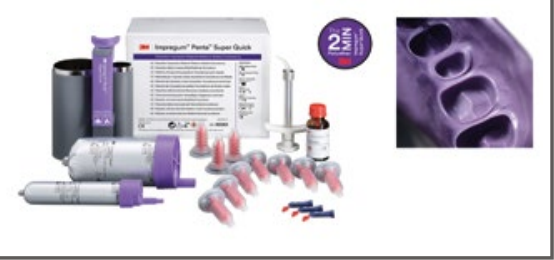

\section{The new all-rounder}

Common reasons for patients to switch practice include the promise of quicker and cheaper treatment.

But practitioners who use COLTENE's new BRILLIANT COMPONEER can deliver efficient, stunning restorative treatment that is also cost effective.

\section{BRILLIANT COMPONEER is a} composite enamel translucent veneer that offers high gloss retention, polishability and stability. It can be used for minimallyinvasive restorations that can be carried out chair-side and for a range of indications. Often, work can be carried out in one session. Results with BRILLIANT COMPONEER are beautiful and stable.

To find out more visit www.coltene. com,emailinfo.uk@coltene.com or call 01444235486.

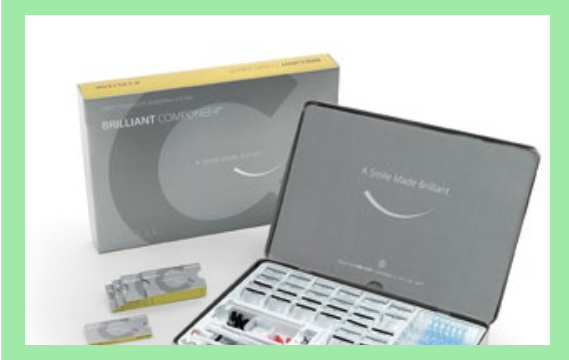

